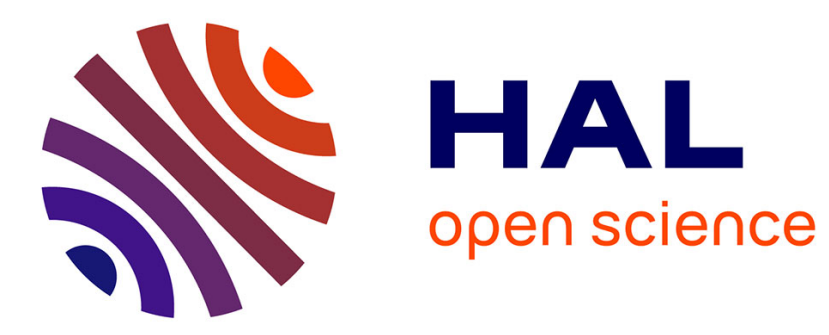

\title{
Assessing the impact of an invasive bryophyte on plant species richness using high resolution imaging spectroscopy
}

Michael Ewald, Sandra Skowronek, Raf Aerts, Jonathan Roger Michel Henri Lenoir, Hannes Feilhauer, Ruben van de Kerchove, Olivier Honnay, Ben Somers, Carol Ximena Garzon-Lopez, Duccio Rocchini, et al.

\section{To cite this version:}

Michael Ewald, Sandra Skowronek, Raf Aerts, Jonathan Roger Michel Henri Lenoir, Hannes Feilhauer, et al.. Assessing the impact of an invasive bryophyte on plant species richness using high resolution imaging spectroscopy. Ecological Indicators, 2020, 110, pp.105882. 10.1016/j.ecolind.2019.105882 . hal-02999071

\section{HAL Id: hal-02999071 \\ https://hal.science/hal-02999071}

Submitted on 10 Nov 2020

HAL is a multi-disciplinary open access archive for the deposit and dissemination of scientific research documents, whether they are published or not. The documents may come from teaching and research institutions in France or abroad, or from public or private research centers.
L'archive ouverte pluridisciplinaire HAL, est destinée au dépôt et à la diffusion de documents scientifiques de niveau recherche, publiés ou non, émanant des établissements d'enseignement et de recherche français ou étrangers, des laboratoires publics ou privés. 
Open Access* version of the published article

Citation:

Ewald M., Skowronek S., Aerts R., Lenoir J., Feilhauer H., Van De Kerchove R., Honnay O., Somers B., Garzón-López C.X., Rocchini D., Schmidtlein S. 2020. Assessing the impact of an invasive bryophyte on plant species richness using high resolution imaging spectroscopy.

Ecological Indicators 110: 105882

https://doi.org/10.1016/j.ecolind.2019.105882

*Elsevier authorized the authors to post this revised personal version of the text of the final journal article on the author's institutional server, incorporating the complete citation and with a link to the Digital Object Identifier (DOI) of the article.

\section{(9)}

Creative Commons Attribution-Noncommercial-Share Alike 2.0 Belgium License

Permissions beyond the scope of this license may be available at http://www.elsevier.com/wps/find/authorsview.authors/copyright\#whatrights 


\title{
Assessing the impact of an invasive bryophyte on plant species richness using high resolution imaging spectroscopy
}

\author{
Michael Ewald ${ }^{1}$, Sandra Skowronek ${ }^{2}$, Raf Aerts ${ }^{3}$, Jonathan Lenoir ${ }^{4}$, Hannes Feilhauer ${ }^{2,5}$, \\ Ruben Van De Kerchove ${ }^{6}$, Olivier Honnay ${ }^{3}$, Ben Somers ${ }^{7}$, Carol Ximena \\ Garzón-López ${ }^{4,8}$, Duccio Rocchini ${ }^{9,10,11}$, and Sebastian Schmidtlein ${ }^{1}$ \\ ${ }^{1}$ Institute of Geography and Geoecology, Karlsruhe Institute of Technology (KIT), \\ Kaiserstr. 12, 76131 Karlsruhe, Germany \\ ${ }^{2}$ Institute of Geography, FAU Erlangen-Nuremberg, Wetterkreuz 15, 91058 Erlangen, \\ Germany \\ ${ }^{3}$ Biology Department, KU Leuven, Kasteelpark Arenberg 31-2435, 3001 Leuven, Belgium \\ ${ }^{4}$ UR "Ecologie et Dynamique des Systèmes Anthropisés" (EDYSAN, UMR 7058 CNRS), \\ Université de Picardie Jules Verne, 1 rue des Louvels, 80037 Amiens Cedex 1, France \\ ${ }^{5}$ Institute for Geographical Sciences, FU Berlin, Malteserstr. 74-100, 12249 Berlin, \\ Germany \\ ${ }^{6}$ VITO Flemish institute for technological research, Boeretang 200, $2400 \mathrm{Mol}$, Belgium \\ ${ }^{7}$ Department of Earth \& Environmental Sciences, KU Leuven, Celestijnenlaan 200E, \\ 3001 Leuven, Belgium \\ ${ }^{8}$ Ecology and Vegetation physiology group (EcoFiv), Universidad de los Andes, Cr. 1E \\ No 18A,Bogotá, Colombia \\ ${ }^{9}$ Department of Biodiversity and Molecular Ecology, Research and Innovation Centre, \\ Fondazione Edmund Mach, Via E. Mach 1, 38010 San Michele all'Adige, TN, Italy \\ ${ }^{10}$ Center Agriculture Food Environment, University of Trento, Via E. Mach 1, 38010 S. \\ Michele all'Adige (TN), Italy \\ ${ }^{11}$ Centre for Integrative Biology, University of Trento, Via Sommarive, 14, 38123 Povo
} (TN), Italy

Remote sensing is commonly used to map the presence of invasive alien plant species across large areas. However, remote sensing also has potential to predict fractional cover, which is more closely linked to the potential ecosystem impact of invasive alien plant species. Here, we mapped the fractional cover of the invasive bryophyte Campylopus introflexus using high resolution imaging spectroscopy ( 233 bands, $490-2430 \mathrm{~nm}, 3 \mathrm{~m} \times 3 \mathrm{~m}$ pixel size) in different habitat types within a coastal dune ecosystem. Maps were predicted 
from generalized partial least squares (gPLS) regression models trained with cover information from 266 field plots $(3 \mathrm{~m} \times 3 \mathrm{~m})$. Models were calibrated using different data subsets, following a spatially blocked subsampling design. In addition, the relationship between $C$. introflexus fractional cover and plant species richness was evaluated using a subset of plot data. Fractional cover estimates from gPLS models resulted in $\mathrm{R}^{2}$ values of $0.64 \pm 0.17$ and an RMSE of $0.14 \pm 0.02$ based on independent validation data. Field observations showed a negative relationship between $C$. introflexus fractional cover and local plant species richness for pixels with a fractional cover above $44 \%$. This threshold was exceeded in $4.3-7.1 \%$ of the studied area depending on the habitat type. Our study demonstrates that remote sensing can be used to map the fractional cover of an invasive bryophyte in a coastal dune ecosystem. Combining cover maps with a threshold value derived from an abundance-impact relationship we were able to highlight areas with potential negative impact on local plant species richness. This method can be implemented on other species and other ecosystem properties affected by plant invasions, al- lowing to highlight potential invasion impacts in a spatially explicit manner.

\section{Introduction}

Invasive alien plant species can have various unwanted consequences, including adverse effects on human health (Shackleton et al., 2019) and ecosystem functioning (Pyšek et al. 2012 Vilà et al., 2011). Impacts on ecosystems include alterations of species richness and composition (Powell et al. 2013), changes in disturbance regimes (Pauchard et al. 2008), or in ecological processes like carbon, nutrient, and water cycling (Aerts et al. 2017, Liao et al., 2008, Rascher et al., 2011). Once an invasive plant species has established within a new range, it is often extremely difficult to eradicate (Rejmanek and J. Pitcairn, 2002). Therefore, the management of established alien species focuses on limiting the most adverse effects (Kumschick et al., 2012). This requires prioritizing management efforts towards the most harmful species and the most valuable habitats (Gaertner et al., 2014; McGeoch et al. 2016). One prerequisite to prioritize these management efforts is the detection and monitoring of invasive plant species (Latombe et al., 2016).

Remote sensing techniques have high potential for monitoring invasive plants over large areas (Rocchini et al., 2015). Many studies have demonstrated the capability of remote sensing approaches to detect invasive plant species and to map their distribution (Vaz et al., 2018). These studies covered a variety of growth forms including trees and shrubs (Lopatin et al., 2019, Somers and Asner, 2013), herbs or grasses (Müllerová et al. 2016; Skowronek et al., 2017a) and even cryptogams (Skowronek et al., 2018). Most commonly, these mapping approaches use classifiers, delivering maps with information on the target species' presence and absence. Yet, remote sensing can also be used to acquire quantitative information on species abundance, such as the fractional cover (e.g. Falkowski et al., 2017; Huang and Geiger, 2008; Miao et al., 2006; Peerbhay et al., 
2016). As the ecosystem impact of an invasive plant species is considerably influenced by its local abundance (Parker et al., 1999, Bradley et al., 2019), remote sensing is offering high potential, not only to map invasive plant species, but also to indicate impact magnitudes across large areas (Ewald et al., 2018, Große-Stoltenberg et al., 2018; Hellmann et al., 2017). However, the potential to link abundance maps with potential invasion impacts has not been fully explored yet. For example, abundance information can be used to compare the invasion severity between different habitat types. Furthermore, abundance maps can be used in combination with abundance-impact relationships to display linkages between the abundance of an invader and specific ecosystem properties (Bradley et al. 2019, Panetta and Gooden, 2017). This combination can be used as spatially explicit indicator of invasion impacts on selected ecosystem properties. Here, we aim to explore this potential. The ability to retrieve plant species covers using imaging remote sensing techniques depends on the size of plant individuals or populations and the pixel-size of the images. Broadly speaking, two scenarios are possible. First, the size of the target individual or population is exceeding the pixel size of the image. This is often the case when using very high resolution remote sensing data in combination with large target individuals, such as shrubs and trees, or large monospecific stands (Gil et al. 2013, Guirado et al., 2017, Kattenborn et al., 2019). Suitable mapping approaches for this scenario include classification approaches, delivering pixel-wise presence-absence information, and object or texture-based approaches (Bradley, 2014). These approaches allow species cover to be calculated from resulting maps across larger areas (Falkowski et al. 2017). In the second scenario, the size of the target individuals or stands is smaller than the pixel size of the used image. In this specific case spectral unmixing approaches and regression techniques can be used to predict fractional cover for single pixels (Asner and Martin, 2008, Miao et al., 2006, Peterson, 2005).

Here, we used airborne imaging spectroscopy to map the fractional cover of the invasive bryophyte Campylopus introflexus - listed among the 100 worst alien plant invaders in Europe (Essl and Lambdon, 2009). In its non-native range C. introflexus is predominately occurring in inland and coastal dunes. In early successional stages it can affect natural succession dynamics (Ketner-Oostra and Sýkora, 2004). Once established, it can form dense mono-specific carpets, locally decreasing species richness within plant communities of dune ecosystems (Biermann and Daniels, 1997, Ketner-Oostra and Sýkora, 2004). Like other mosses, C. introflexus is capable of retaining water and nutrients from precipitation, and therefore is suspected to influence biomass accumulation, soil formation, and micro-climate (Ayres et al., 2006, Essl et al., 2014). Moreover, C. introflexus was reported to influence the species composition of carabid beetles and spiders in coastal dunes (Vogels et al., 2005). Using the fractional cover derived from predicted maps as a proxy for local abundance, we aimed to evaluate the impact of $C$. introflexus on plant species richness within a dune habitat in a spatially explicit manner. The specific research questions were:

1. How accurately can the fractional cover of the invasive moss $C$. introflexus be mapped in different habitats using airborne imaging spectroscopy data?

2. Which spectral bands are the most important to predict fractional cover of $C$. 
introflexus?

3. Which habitat type shows the highest level of invasion?

4. At which fractional cover can we expect an impact on local plant species richness?

\section{Materials and Methods}

\subsection{Study area}

The study area covers the coastal dune ecosystem in the western part of the island of Sylt $\left(54^{\circ} 55^{\prime} \mathrm{N}, 8^{\circ} 20^{\prime} \mathrm{E}\right)$ located in northern Germany (Fig. 1). The climate is temperate oceanic with a mean annual temperature of $9^{\circ} \mathrm{C}$ and mean annual precipitation of $715 \mathrm{~mm}$. The western coastline of Sylt has a north-to-south distance of approximately $35 \mathrm{~km}$ with protected dunes covering an area of $27.7 \mathrm{~km} 2$. Habitats are characterized by a narrow belt of shifting sand dunes along the shoreline and vast areas of decalcified fixed dunes with herbaceous or dwarf shrub vegetation (Fig. 2, Table 1). In the northern part of the island, dunes are grazed by sheep. The predominant soil types are sandy loose immature soils and podsolized regosols both characterized by low organic matter content. The vegetation of the shifting dunes is characterized by grassland dominated by Ammophila arenaria (code 2120 according to the European Union Habitat Directive). Decalcified fixed dunes are characterized by heath vegetation dominated by Empetrum nigrum (code 2140; further referred to as crowberry heath, Table 1, Fig. 2), or by herbaceous vegetation with Carex arenaria, Corynephorus canescens, and Hypochaeris radicata as the characteristic species (code 2130; further regarded as grey dunes, Table 1. Fig. 2). Frequently occurring dune slacks, which are periodically flooded by precipitation water, represent the floristically most valuable habitats (code 2190, Table 1, Fig. 2). The vegetation in dune slacks is characterized by Erica tetralix and Vaccinium uliginosum with frequent occurrences of red-listed plant species like Drosera rotundifolia, D. intermedia and Pedicularis sylvatica. Campylopus introflexus is present across the entire island, mainly occurring in the fixed dunes with little windblown sand intake. The species is locally forming huge and dense populations with growth heights up to $8 \mathrm{~cm}$.

\subsection{Study species}

Campylopus introflexus was first observed in Europe in 1941, and has by now spread across major parts of the continent (Hassel and Soderstrom, 2005). On the island of Römö it was first noticed in 1970 (Frahm, 1971), and probably also introduced on the neighboring island of Sylt around the same time. Growing on bare sand, C. introflexus is predominately occurring in coastal dunes (Essl et al., 2014).

\section{Vegetation data}

Field data were acquired between June and November 2014, across 287 plots of $3 \mathrm{~m} \times$ $3 \mathrm{~m}$ surface area. Ninety of these plots were selected in situ in order to cover sites with 

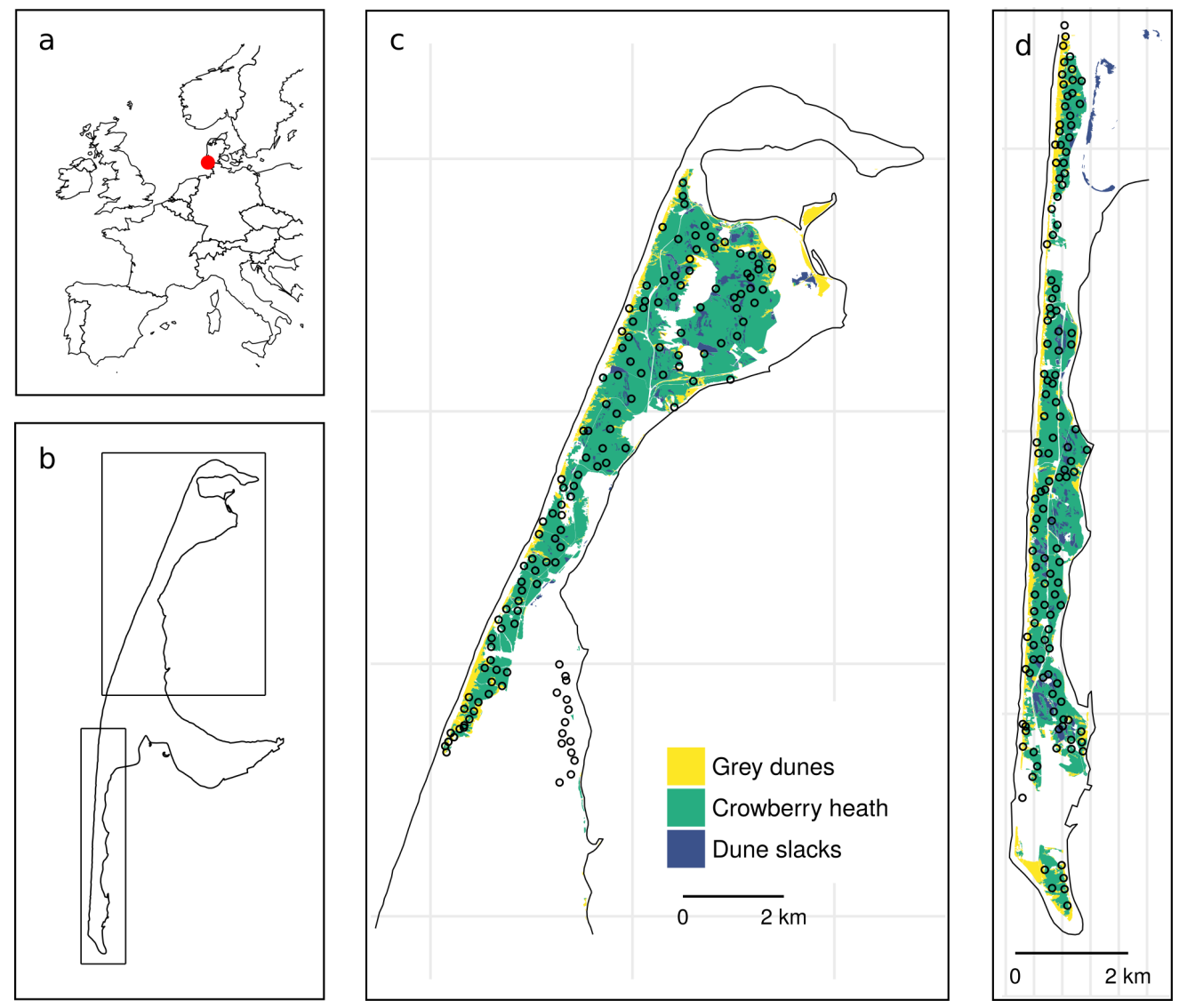

Figure 1 Location of the study area (a), outline of the island of Sylt (b) and habitat maps including plot locations for the northern (c) and southern part of the island (d).

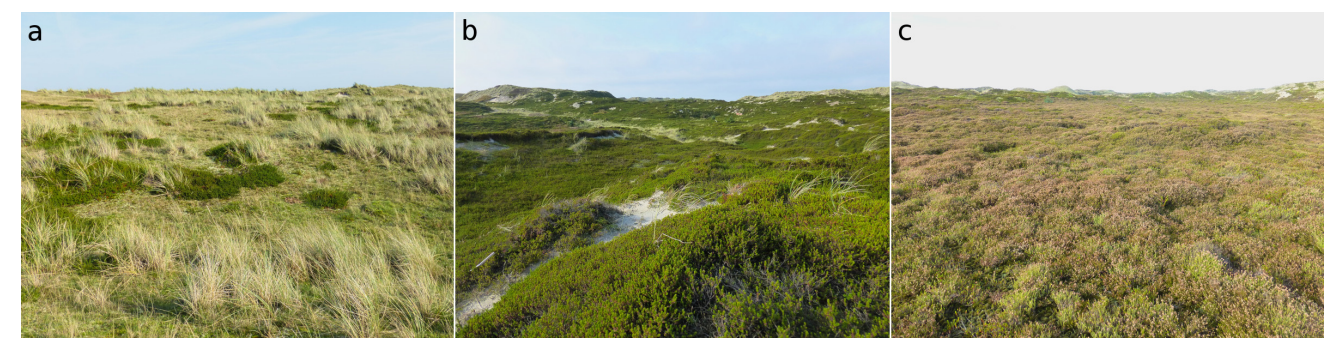

Figure 2 Habitat types included in this study; a: grey dunes, b: crowberry dunes, c: dune slacks (photos by S. Skowronek).

no presence $(\mathrm{n}=30)$, low $(\leq 30 \%, \mathrm{n}=31)$ and medium to high fractional cover $(>30 \%$, $\mathrm{n}=29$ ) of $C$. introflexus. Apart from the cover of $C$. introflexus, we also recorded the percentage cover of all co-occurring vascular plant and moss species in these 90 plots. For the 197 remaining plots, we only recorded the percentage cover of $C$. introflexus. These additional plots were randomly located to cover all relevant habitat types across the study area. For each of the 287 plots we recorded the center coordinates. In addition 
to the field data, for each plot, habitat types according to the Habitats Directive of the European union were derived from biotope maps of the year 2012 (Fig 1. Table 1) Leguan, 2012).

Table 1 Habitat types included in this study and total coverage across the Island of Sylt. \# Training plots: number of plots included in the dataset used for model calibration. The remaining plots covered other habitat types.

\begin{tabular}{|c|c|c|c|}
\hline Used Acronym & Description & Area $\left(\mathrm{km}^{2}\right)$ & \# Training plots \\
\hline Grey dunes & Fixed coastal dunes with herbaceous vegetation & 3.3 & 44 \\
\hline Crowberry dunes & Decalcified fixed dunes with Empetrum nigrum & 15.1 & 167 \\
\hline Dune slacks & Humid dune slacks & 1.6 & 13 \\
\hline
\end{tabular}

\section{Remote sensing data}

Airborne imaging spectroscopy data were acquired on July 16 2014, between 12:21 and 13:13 local time (UTC+2), using the APEX (Airborne Prism EXperiment) sensor at a flight height of $2270 \mathrm{~m}$ with flight lines in a north-to-south direction. The data included images of 285 spectral bands covering a spectral range from $412 \mathrm{~nm}$ to $2432 \mathrm{~nm}$ with a pixel size of $1.8 \mathrm{~m} \times 1.8 \mathrm{~m}$. Imaging spectroscopy data was geometrically and atmospherically corrected using the standard procedures applied to APEX data (Sterckx et al. 2016, Vreys et al., 2016). To verify atmospheric correction, ground samples were taken in September 2014 from 15 different locations at the beach and at large parking lots (serving as virtual invariant features) using a full-range field spectrometer (FieldSpec 4JR, ASD Inc., Longmont, USA).

Noisy bands between $410 \mathrm{~nm}$ and $480 \mathrm{~nm}$, and bands in the range between $1320 \mathrm{~nm}$ and $1450 \mathrm{~nm}$ and between $1670 \mathrm{~nm}$ and $1990 \mathrm{~nm}$, being affected by atmospheric water absorption, were excluded from subsequent analyses. This resulted in a total of 233 predictor variables. To minimize the influence of shadows, we subjected the spectra to brightness normalization (Feilhauer et al. 2010$)$. To meet the size of the field plots, the spatial resolution of spectral images was resampled to a pixel size of $3 \mathrm{~m} \times 3 \mathrm{~m}$. Resampling was necessary because cover estimations were based on a surface area of $3 \mathrm{~m} \times 3 \mathrm{~m}$, and also because we intended to link the predicted maps with information derived from abundance-impact relationships based on plots of the same size.

For each of the 287 plots, we extracted the brightness normalized reflectance values from all pixels overlapping with the plot area. This resulted in up to four spectra originating from different neighboring pixels per plot. From these values we calculated the weighted mean for each band using the percentage overlap of each pixel with the respective plot area as weight.

\subsection{Generalized partial least squares regression}

To model the fractional cover of $C$. introflexus, we ran generalized partial least squares (gPLS) regression models using the field-derived cover values as the response variable. 
Like classical partial least squares (PLS) regression, gPLS is a combined method of dimension reduction and regression that can deal with a high number of predictor variables, and also with high collinearity among the predictor variables (Bastien et al. 2005 Wold et al. 1984). For this reason, it is often used to link a response variable to hyperspectral remote sensing data, in which adjacent bands are often highly correlated and the number of predictors is exceeding the number of observations used to train the model. Similar to other dimension reduction methods like principle component analyses, in a PLS regression the information content of a dataset is translated into $\mathrm{n}$ latent variables, also called components, which are aligned orthogonally in the n-dimensional feature space determined by the $\mathrm{n}$ initial variables. In classical PLS regression, components are linked to the response variable using a least squares regression. In a gPLS, this regression is replaced by a general linear regression that can be fit to response variables ranging from 0 to 1 (Bastien et al. 2005). For the purpose of improving the prediction performance (remove noise) and for a better understanding of the model, a variable selection can be useful (Mehmood and Ahmed, 2016).

Because our response variable ranged from 0 to 1 , we chose to calculate a gPLS with a logit-link function. Models were calculated using the package plsRglm 1.1.1 (Bertrand et al. 2014) in R 3.4.4 (R Core Team, 2018). The northern end of the island was excluded from modeling because the specific vegetation community was under-represented in the dataset. We therefore also dropped data from 21 field plots located in that area. This resulted in a total of 266 plots, including 162 absence plots used in the final training dataset. All predictor variables were scaled to a mean value of 0 and a standard deviation of 1 to allow direct comparisons among estimated coefficients.

To prevent a possible underestimation of the prediction errors, model calculations were ran repeatedly using 10 different data subsets resulting from a spatially blocked subsampling procedure (Roberts et al. 2017). Based on their coordinates, field plots were divided into ten clusters using k-means clustering. For each dataset, $20 \%$ of the field plots were held back for independent validation, each time selecting the plots closest to the center coordinates of the respective clusters.

For the selection of relevant spectral bands, model calculations were additionally embedded in a 10-fold cross validation procedure. Bands were selected based on a stepwise backward variable selection procedure using the standardized coefficients as selection criteria. In each step we dropped $10 \%$ of the predictor variables using the following procedure. We implemented a non-parametric bootstrap approach with 250 bootstrap iterations. For each bootstrap iteration, we recalculated gPLS regression models. Standardized coefficients for each predictor variable resulting from the 250 bootstrap iterations were then tested for significant difference from zero using a $95 \%$ confidence interval $(\mathrm{p}<0.05)$. Using the test results, we dropped predictor variables with insignificant standardized coefficient starting with those having the smallest mean absolute value.

For all models calculated in each step the optimal number of latent variables was selected based on the lowest Akaike Information Criterion (AIC) value. To prevent overfitting, we additionally limited the maximum number of latent variables to five. The procedure stopped when less than $10 \%$ of the remaining predictor variables showed insignificant standardized coefficients. From all steps the model associated with the 
lowest RMSE in 10-fold cross validation was selected as final model. For each model calculated with different data subsets, we calculated prediction maps representing the fractional cover of $C$. introflexus within each pixel. From these maps we calculated median maps representing pixel-wise medians of predicted values.

\subsection{Model evaluation}

The model's predictive performances were evaluated by calculating two sets of Pearson $\mathrm{R}^{2}$ values and root mean square error (RMSE) values based on training and independent validation data respectively. To obtain the overall predictive performance, we calculated the mean and standard error for both $\mathrm{R}^{2}$ and RMSE values.

The relative importance of each spectral band was derived by calculating model predictions based on permuted predictor datasets. For each model, permuted datasets were created by successively randomizing the values of each predictor variable. For each permuted dataset, we re-calculated model predictions based on the original response data. Predicted values calculated from permuted datasets were then compared to the predictions from the non-permuted dataset, calculating the Pearson correlation coefficient. A high correlation coefficient indicates that a predictor (here: spectral band) is not better than a random predictor variable. In contrast, a small coefficient indicates high relevance. Accordingly, the inverse correlation coefficient was then used as variable importance of each predictor variable.

Model residuals were used to compare prediction errors for different habitat types. To get a picture from all model residuals, we ran a linear mixed-effects model (LMM) using the residuals from all models as response variable and habitat type as fixed-effect variable. The data subsets were numbered from 1 to 10 and included as random intercepts. We ran LMMs using the nlme 3.1 (Pinheiro et al., 2018) package in R.

\subsection{Evaluating the impact of $C$. introflexus}

To evaluate the abundance of $C$. introflexus in different habitat types, we calculated mean fractional covers and the total cover for each type. First, average covers were calculated from each of the 10 prediction maps for each habitat type. As a second step, we calculated the mean and standard error from these values. Total cover was derived by multiplying mean fractional cover with the total area covered by each habitat type, respectively.

To assess the impact of $C$. introflexus on native plant communities, we evaluated the relationship between its fractional cover and the richness of co-occurring plant species based on data acquired in 90 field plots. We used the Simpson diversity index (Simpson, 1949) for plant species richness, including all vascular plant and moss species. This abundance-impact relationship was analyzed by fitting a linear model. The Simpson index was used as response variable and the percentage cover of $C$. introflexus, both the first- and second-order polynomial term, was used as explanatory variable. To identify existing break points in this relationship, we ran a piecewise regression using the segmented 3.0 package in $\mathrm{R}$ (Muggeo, 2008, 2003). 


\subsection{Results}

Models resulted in mean $\mathrm{R}^{2}$ values of 0.71 (standard error: \pm 0.03 ), and $0.64 \pm 0.17$ as well as mean RMSE values of $0.12 \pm 0.01$ and $0.14 \pm 0.02$ based on the training (Fig. 3 and independent validation datasets, respectively (Appendix A1).

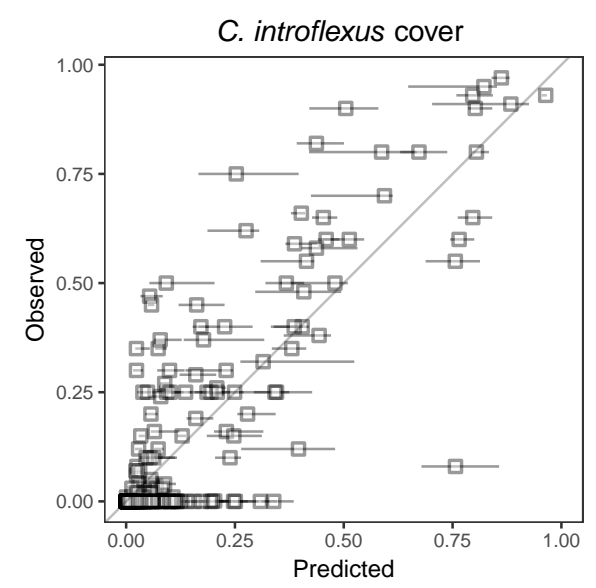

Figure 3 Median predicted values retrieved from generalized partial least squares regression models vs. observed values for the fractional cover of $C$. introflexus in $3 \mathrm{~m} \times 3 \mathrm{~m}$ plots from 10 training datasets. Error bars represent ranges between the $25 \%$ quantile and the $75 \%$ quantile of model predictions.

The ten final models included a range of 7-183 spectral bands after variable selection. All models included bands situated in the shortwave-infrared region (SWIR), between $2150 \mathrm{~nm}$ and $2160 \mathrm{~nm}$ as well as between $2240 \mathrm{~nm}$ and $2250 \mathrm{~nm}$ (Fig. 4). The bands located around $2242 \mathrm{~nm}$ and $2248 \mathrm{~nm}$ had highest mean variable importance. Prediction errors differed between the habitat types, indicating highest prediction accuracy for crowberry heath and lowest accuracy for dune slacks (Fig. 5).

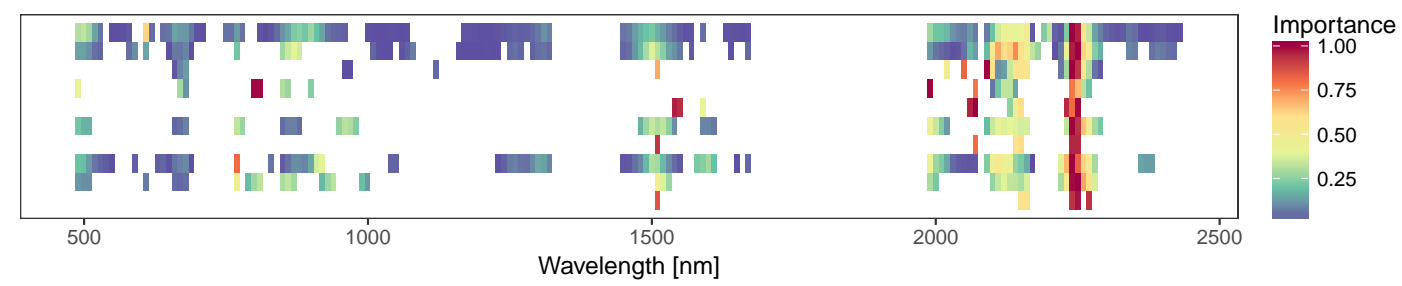

Figure 4 Relative importances of spectral bands included in 10 gPLS models using different training datasets.

Based on the median predictions C. introflexus total cover across the island of Sylt reached $2.08 \mathrm{~km} 2$. Mean cover of $C$. introflexus ranged from $10.2 \pm 0.9 \%$ in crowberry heath to $11.1 \pm 1.0 \%$ in grey dunes (Table 2).

The linear model relating fractional cover of $C$. introflexus to plot level plant species richness resulted in a $\mathrm{R}^{2}$ value of 0.10 . The predicted curve peaks at about $30 \%$ cover 


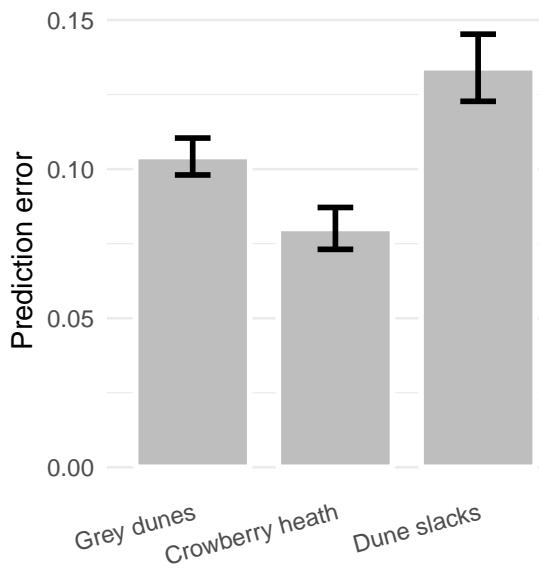

Figure 5 Prediction error of $C$. introflexus fractional cover for different habitat types. Displayed values represent absolute deviations of predicted covers from observed covers calculated using a linear mixed effects model including all deviations resulting from repeated gPLS model calculations.

Table 2 Fractional covers of $C$. introflexus for different habitat types based on predicted maps. Mean cover represents mean pixel values for each habitat type averaged for all calculated maps. The total coverage is giving the total area covered by $C$. introflexus.

\begin{tabular}{lrr}
\hline Habitat & Mean cover $(\%)$ & Total coverage $\left(\mathbf{k m}^{\mathbf{2}}\right)$ \\
\hline Grey dunes & $11.1 \pm 1.0$ & 0.37 \\
Crowberry heath & $10.2 \pm 0.9$ & 1.54 \\
Dune slacks & $10.6 \pm 1.9$ & 0.17 \\
\hline
\end{tabular}

of C. introflexus (Fig. 6). The piecewise regression analysis resulted in a break point at a fractional cover of $44 \%$. Above this threshold increasing cover of C. introflexus was related to decreasing plant species richness within plots of $3 \mathrm{~m} \times 3 \mathrm{~m}$ surface area. Prediction maps indicated that $7.1 \%, 4.3 \%$, and $6.8 \%$ of the pixels were characterized by fractional covers of $44 \%$ or above, for grey dunes, crowberry heath and dune slacks, respectively (Fig. 7).

\section{Discussion}

\subsection{Mapping the fractional cover of $C$. introflexus}

We demonstrated that imaging spectroscopy can be used to map the fractional cover of an invasive alien bryophyte. Similar results for mapping invasive alien plant species cover have been found by previous studies, however in different contexts. For example, Peterson (2005) used multi-seasonal Landsat 7 images to map the cover of a non-native grass species using regression approaches. Guo et al. (2018), predicted the fractional cover of an invasive grass species using hyperspectral data derived from field spectroscopy. Similarly, spectral mixture analyses can be used to predict the fractional cover of selected target species (Andrew and Ustin, 2008; Somers et al., 2011). For example, Asner and 


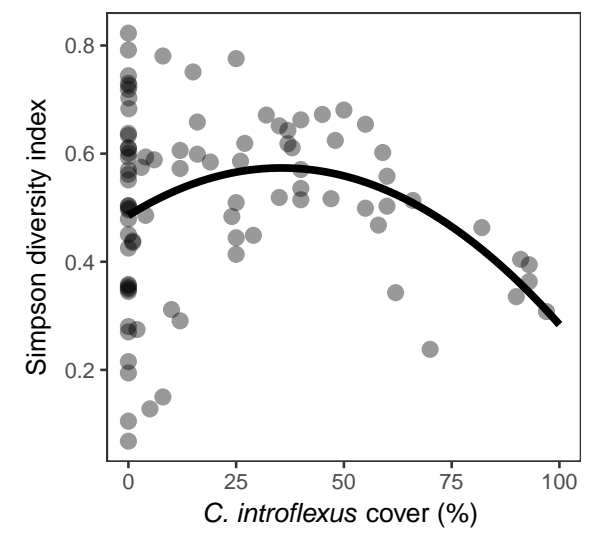

Figure 6 Relationship between $C$. introflexus cover and plant species richness given by the Simpson diversity index observed for 90 field plots $(3 \mathrm{~m} \times 3 \mathrm{~m})$ and predicted using a linear model.

Martin (2008) predicted the cover of several non-native tree species in a rainforest from imaging spectroscopy data using a spatial unmixing approach. In line with these previous studies, our results underline the high potential of remote sensing to map fractional cover of invasive alien plant species. Future remote sensing approaches should focus on mapping quantitative data, such as fractional cover, as they provide more information than qualitative (presence-absence) data.

Similar to presence-absence mapping one major requirement for the success of mapping species cover is that the spectral signal of the target species differs from that of the background vegetation (Bradley, 2014). In our study, plots with a high C. introflexus cover were spectrally different from those without presence (Appendix A2). Reflectance spectra of $C$. introflexus were characterized by higher reflectance in the short wave infrared (SWIR) and lower reflectance in the near infrared (NIR), compared to the dominating vascular plant species of the studied habitat types. This finding is in contrast to Bubier et al. (1997) who found lower canopy reflectance for mosses compared to vascular plant species in both the NIR and SWIR. In the case of $C$. introflexus, high SWIR reflectance is probably due to the high proportion of windblown sand that intermingles with the moss carpets. Although reflectance differed between $C$. introflexus and the co-occurring vegetation across large parts of the spectrum, variable importance indicated that only distinct sections were important for predicting fractional cover. The high importance of spectral bands in the SWIR for the prediction of $C$. introflexus cover can be attributed to differences in leaf structure or water content (Jacquemoud et al., 2009, Kokaly et al., 2009). Leaf water content can differ substantially between vascular plant species and mosses such as $C$. introflexus. Furthermore, in contrast to vascular plants, mosses are characterized by only a very thin cuticle and thus differ in leaf structure (Glime, 2017). Therefore, it is likely that selected spectral bands in the SWIR allow a discrimination of different C. introflexus covers from co-occurring vascular plant species. Furthermore, spectral bands in the SWIR may have helped to discriminate $C$. introflexus from bare soil. 
a
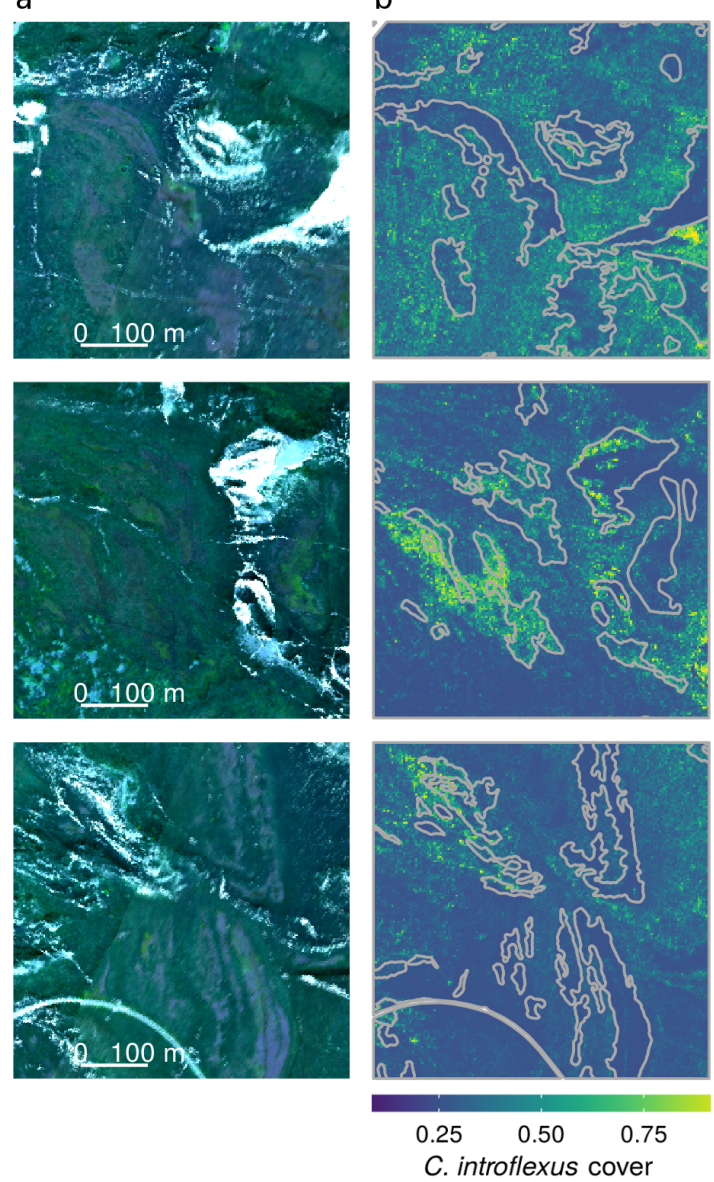

b
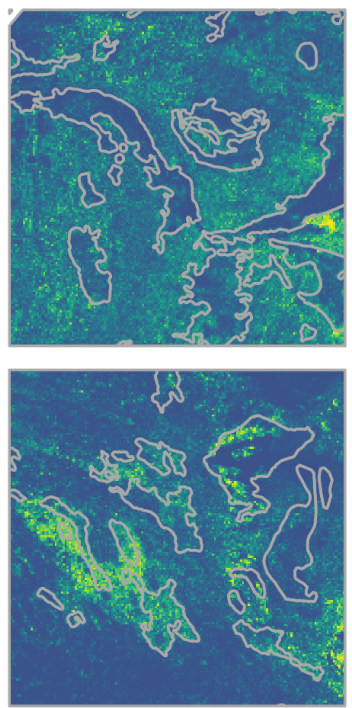
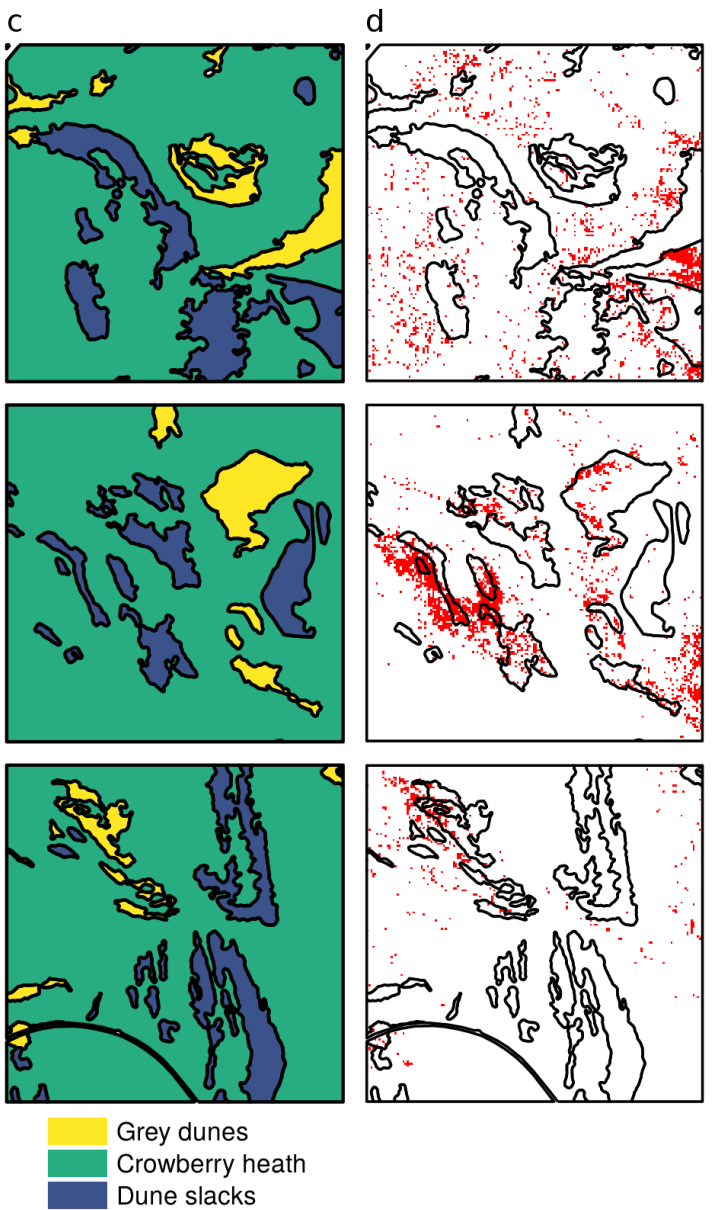

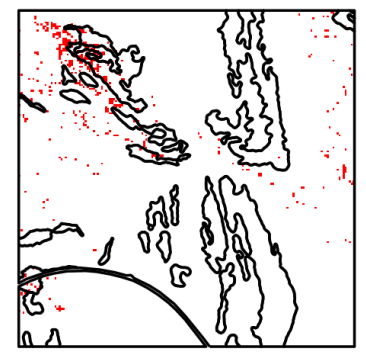

h.

Figure 7 Map examples showing (a) an RGB image (b) the predicted fractional cover of $C$. introflexus (c) a map of habitat types and (d) pixels with fractional covers higher than 0.44 (in red) indicating potential negative impact on plant species richness.

The high importance of spectral bands located in NIR in some of the calculated models (Fig. 4) can be attributed to differences in canopy structure. In contrast to most of the co-occurring species, C. introflexus carpets are characterized by a very homogeneous and dense canopy, allowing only little within-canopy scattering of incoming radiation Ollinger (2011). The NIR was also recognized to be important for the discrimination of different moss species (Bubier et al., 1997). In contrast to structural properties, differences in pigment concentration can be excluded to be important for predicting $C$. introflexus cover, as characteristic bands in the visible region of the spectrum did not play an important role in the models (Ustin et al. 2009).

It is important to note that Skowronek et al. (2018), using the same hyperspectral images, found different bands to be important for predicting the presence and absence of $C$. introflexus. This previous study located important bands in the $1700-1750 \mathrm{~nm}$ region and around $2000 \mathrm{~nm}$. This suggests that discriminating abundances of one species 
may require different spectral information than discriminating between presences and absences. Similar to Skowronek et al. (2018), we identified distinct narrow bands in the SWIR to be important for mapping $C$. introflexus. This suggests that hyperspectral data is necessary for mapping $C$. introflexus, as SWIR bands from multispectral sensors usually cover wavelength ranges that are too broad (e.g. Sentinel 2, Landsat 8). Prediction accuracies differed between the habitat types, indicating less-accurate cover predictions for dune slacks and grey dunes in comparison to crowberry heath. Lower accuracies for dune slacks can probably be attributed to the small sample size (Table 1). For grey dunes, lower accuracies can presumably be attributed to the spectral variability that was highest in this habitat type (Appendix A3). In contrast to the two evergreen heath habitats, grey dunes were characterized by a higher cover of grasses and herbs, that show stronger phenological variation. We assume that the high spectral variability observed for grey dunes was caused by the variable proportion of senescent leaves we observed in some of the plots. Furthermore, grey dune plots were more variable concerning bare soil coverage. Previous studies showed that the mapping accuracy of species is influenced by the spectral variability of the studied habitat (Andrew and Ustin, 2008, Somers et al., 2011). In addition, grey dunes and $C$. introflexus canopies seem to be spectrally less different compared to the other habitat types (Appendix A3). This may be due the higher influence of other native moss species on the canopy reflectance of grey dunes or due to the higher bare soil coverage compared to other habitat types. When mapping plant species, high spectral similarity between the target species and its background vegetation may influence prediction accuracies negatively (Andrew and Ustin, 2008). Apart from found differences in prediction accuracies, our results indicate that imaging spectroscopy is suited for cover predictions in different habitat types and hence also for comparing the potential impact of invasive plant species in these habitat types.

As $C$. introflexus does not exhibit strong phenological variation, it is likely that the results from our study can be transferred to other similar study areas. A previous study by Skowronek et al. (2018) showed that model transfer is promising when predicting presence-absence of this species. However, as for other moss species, spectral characteristics may strongly vary with water content and thus with local weather conditions (Neta et al., 2011).

\subsection{Evaluating the impact of $C$. introflexus}

This study demonstrates that remote sensing data can be used to evaluate the level of invasion in different habitat types. Our results indicate that $C$. introflexus is most abundant in grey dunes, in agreement with the findings of Klinck (2009). As the local abundance is one of the determining factors for the impact magnitude of an invasive alien species, cover maps can be used as baseline information for the potential impact of $C$. introflexus. Such information covering different habitat types can be helpful to prioritize limited management resources.

In our specific case, average fractional cover for $C$. introflexus was in the same order of magnitude for the three habitat types. Cover values derived from prediction maps 
were slightly higher than observed in the 160 randomly placed field plots (mean fractional cover of $9 \%, 5 \%$ and $6 \%$ for crowberry heath, grey dunes and dune slacks, respectively). This may be because the discrete field sampling missed relevant spatial variation in $C$. introflexus fractional cover. Furthermore, differences may be caused by uncertainties of the used mapping approach. Potential difficulties may arise from its unreliability to detect low cover occurrences at the sub-pixel level (Bradley, 2014). For example Skowronek et al. (2017b) found that the detection of $C$. introflexus becomes unreliable when the species is covering less than one third of the pixel size. We therefore do not expect that this approach can be used to differentiate between low cover and absence. However, it has high potential to discriminate between low, medium and high abundance areas, and thus can indicate the magnitude of potential invasion effects.

To highlight invasion impacts concerning specific ecosystem properties, cover maps can be combined with abundance-impact relationships. Here we studied the relationship between $C$. introflexus cover and the species richness of co-occurring plant species. Our results suggest a cover threshold of $44 \%$ above which increasing cover of $C$. introflexus is related to decreasing plant species richness. In combination with a cover map, this threshold can be used to highlight high impact areas in a spatially explicit manner. Previous studies found variable abundance-impact relationships strongly depending on the target species and studied variables (e.g. Bradley et al., 2019, Fried and Panetta, 2016, Gooden et al., 2009; McAlpine et al., 2015; Große-Stoltenberg et al., 2018). It is important to note that thresholds derived from abundance-impact relationships should be applied with caution because they do not necessarily imply a causal link between invasive species abundance and a specific ecosystem property. Still, abundance or cover thresholds are meaningful, particularly to prioritize the control of established invaders in valuable habitats (Panetta and Gooden, 2017). Regarding our case study it should also be considered that invasive alien plants may affect some native species or functional groups even at lower abundance levels, than indicated by the threshold (Panetta and Gooden, 2017). For example, interactions of $C$. introflexus with other mosses and lichens are not specifically displayed in the threshold defined in this study and should be subject to further investigations. Here, particularly long term effects on natural succession dynamics are not fully understood (Hasse, 2007). Cover maps created from remote sensing time series could help study these dynamics at the landscape level.

\section{Conclusion}

In this study, we successfully mapped the fractional cover of an invasive alien moss C. introflexus using imaging spectroscopy. Important spectral bands for the prediction of covers were situated in the SWIR, suggesting that variation in cover was related to differences in leaf water content and leaf structure between $C$. introflexus and the co-occurring native vegetation. Resulting maps can be used as baseline information to study potential impact on ecosystem functioning, because the local abundance of invasive alien species is one of the determinants to explain their impact magnitude. We showed that cover maps can be used to evaluate the level of invasion in different 
habitat types. Furthermore, cover maps in combination with thresholds derived from cover-impact relationships might be useful to highlight areas of particular concern. Both outputs represent valuable information to prioritize management of established invasive alien species.

\section{Acknowledgements}

This study is part of the project DIARS (Detection of invasive plant species and assessment of their impact on ecosystem properties through remote sensing) funded by the ERA-Net BiodivERsA, with the national funders: ANR (Agence Nationale de la Recherche); BelSPO (Belgian Federal Science Policy Office); and DFG (Deutsche Forschungsgemeinschaft). Michael Ewald was funded through the DFG research grant SCHM 2153/9-1. Furthermore this study was supported by the INPANT project (SR/01/ 321) within the STEREOIII program funded by the BelSPO. Data processing and the calculation of prediction maps was supported by the computational resource bwUniCluster funded by the Ministry of Science, Research and the Arts and the Universities of the State of Baden-Württemberg, Germany, within the program bwHPC. The authors would like to thank the nature conservation authority of Northern Friesland and private land owners for providing maps and granting permission to access the study area.

\section{References}

Aerts, R., Ewald, M., Nicolas, M., Piat, J., Skowronek, S., Lenoir, J., Hattab, T., Garzón-López, C.X., Feilhauer, H., Schmidtlein, S., Rocchini, D., Decocq, G., Somers, B., Van De Kerchove, R., Denef, K., Honnay, O., 2017. Invasion by the alien tree Prunus serotina alters ecosystem functions in a temperate deciduous forest. Frontiers in Plant Science 8, 179. doi:10.3389/fpls.2017.00179.

Andrew, M.E., Ustin, S.L., 2008. The role of environmental context in mapping invasive plants with hyperspectral image data. Remote Sensing of Environment 112, 43014317. doi:10.1016/j.rse.2008.07.016.

Asner, G.P., Martin, R.E., 2008. Spectral and chemical analysis of tropical forests: Scaling from leaf to canopy levels. Remote Sensing of Environment 112, 3958-3970. doi:10.1016/j.rse.2008.07.003.

Ayres, E., van der Wal, R., Sommerkorn, M., Bardgett, R.D., 2006. Direct uptake of soil nitrogen by mosses. Biology Letters 2, 286-288. doi:10.1098/rsbl.2006.0455.

Bastien, P., Vinzi, V.E., Tenenhaus, M., 2005. PLS generalised linear regression. Computational Statistics \& Data Analysis 48, 17-46. doi:10.1016/j.csda.2004.02.005

Bertrand, F., Meyer, N., Maumy-Bertrand, M., 2014. Partial least squares regression for generalized linear models, $\mathrm{R}$ package version 1.1.1. 
Biermann, R., Daniels, F.J.A., 1997. Changes in a lichen-rich dry sand grassland vegetation with special reference to lichen synusiae and Campylopus introflexus. Phytocoenologia 27, 257-273. doi:10.1127/phyto/27/1997/257.

Bradley, B.A., 2014. Remote detection of invasive plants: a review of spectral, textural and phenological approaches. Biological Invasions 16, 1411-1425. doi:10.1007/ s10530-013-0578-9.

Bradley, B.A., Laginhas, B.B., Whitlock, R., Allen, J.M., Bates, A.E., Bernatchez, G., Diez, J.M., Early, R., Lenoir, J., Vilà, M., Sorte, C.J.B., 2019. Disentangling the abundance-impact relationship for invasive species. Proceedings of the National Academy of Sciences , 201818081doi:10.1073/pnas.1818081116

Bubier, J.L., Rock, B.N., Crill, P.M., 1997. Spectral reflectance measurements of boreal wetland and forest mosses. Journal of Geophysical Research: Atmospheres 102, 2948329494. doi:10.1029/97JD02316.

Essl, F., Lambdon, P.W., 2009. Alien bryophytes and lichens of europe, in: Handbook of Alien Species in Europe. Springer Netherlands, Dordrecht, pp. 29-41. doi:10.1007/ 978-1-4020-8280-1_3.

Essl, F., Steinbauer, K., Dullinger, S., Mang, T., Moser, D., 2014. Little, but increasing evidence of impacts by alien bryophytes. Biological Invasions 16, 1175-1184. doi:10. 1007/s10530-013-0572-2.

Ewald, M., Skowronek, S., Aerts, R., Dolos, K., Lenoir, J., Nicolas, M., Warrie, J., Hattab, T., Feilhauer, H., Honnay, O., Garzón-López, C.X., Decocq, G., Kerchove, R.V.D., Somers, B., Rocchini, D., Schmidtlein, S., 2018. Analyzing remotely sensed structural and chemical canopy traits of a forest invaded by $<$ Emphasis Type $=$ "Italic" $>$ Prunus serotina $</$ Emphasis $>$ over multiple spatial scales. Biological Invasions , 1-15doi:10.1007/s10530-018-1700-9.

Falkowski, M.J., Evans, J.S., Naugle, D.E., Hagen, C.A., Carleton, S.A., Maestas, J.D., Khalyani, A.H., Poznanovic, A.J., Lawrence, A.J., 2017. Mapping tree canopy cover in support of proactive prairie grouse conservation in western north America. Rangeland Ecology \& Management 70, 15-24. doi $10.1016 /$ j.rama.2016.08.002.

Feilhauer, H., Asner, G.P., Martin, R.E., Schmidtlein, S., 2010. Brightness-normalized partial least squares regression for hyperspectral data. Journal of Quantitative Spectroscopy and Radiative Transfer 111, 1947-1957. doi:10.1016/j · jqsrt.2010.03.007.

Frahm, J.P., 1971. Campylopus introflexus (Hedw.) Brid. neu für Dänemark. Lindbergia $1,117-118$.

Fried, G., Panetta, F.D., 2016. Comparing an exotic shrub's impact with that of a native life form analogue: Baccharis halimifolia vs Tamarix gallica in Mediterranean salt marsh communities. Journal of Vegetation Science 27, 812-823. doi:10.1111/ jvs.12407. 
Gaertner, M., Biggs, R., Te Beest, M., Hui, C., Molofsky, J., Richardson, D.M., 2014. Invasive plants as drivers of regime shifts: identifying high-priority invaders that alter feedback relationships. Diversity and Distributions 20, 733-744. doi:10.1111/ddi. 12182 .

Gil, A., Lobo, A., Abadi, M., Silva, L., Calado, H., 2013. Mapping invasive woody plants in Azores Protected Areas by using very high-resolution multispectral imagery. European Journal of Remote Sensing 46, 289-304. doi:10.5721/EuJRS20134616.

Glime, J., 2017. Bryophyte Ecology Volume 1: Physiological Ecology. Michigan Technological University, Michigan.

Gooden, B., French, K., Turner, P.J., Downey, P.O., 2009. Impact threshold for an alien plant invader, Lantana camara L., on native plant communities. Biological Conservation 142, 2631-2641. doi:10.1016/j.biocon.2009.06.012.

Große-Stoltenberg, A., Hellmann, C., Thiele, J., Werner, C., Oldeland, J., 2018. Early detection of GPP-related regime shifts after plant invasion by integrating imaging spectroscopy with airborne LiDAR. Remote Sensing of Environment 209, 780-792. doi:10.1016/j.rse.2018.02.038.

Guirado, E., Tabik, S., Alcaraz-Segura, D., Cabello, J., Herrera, F., 2017. Deep-learning versus OBIA for scattered shrub detection with google earth imagery: Ziziphus lotus as case study. Remote Sensing 9, 1220. doi:10.3390/rs9121220.

Guo, Y., Graves, S., Flory, S.L., Bohlman, S., 2018. Hyperspectral measurement of seasonal variation in the coverage and mipacts of an invasive grass in an experimental setting. Remote Sensing 10, 784. doi:10.3390/rs10050784.

Hasse, T., 2007. Campylopus introflexus invasion in a dune grassland: succession, disturbance and relevance of existing plant invader concepts. Herzogia 20, 305-315.

Hassel, K., Soderstrom, L., 2005. The expansion of the alien mosses Orthodontium lineare and Campylopus introflexus in Britain and continental Europe. Journal of the Hattori Botanical Laboratory, 183-194.

Hellmann, C., Große-Stoltenberg, A., Thiele, J., Oldeland, J., Werner, C., 2017. Heterogeneous environments shape invader impacts: integrating environmental, structural and functional effects by isoscapes and remote sensing. Scientific Reports 7, 4118. doi:10.1038/s41598-017-04480-4

Huang, C.y., Geiger, E.L., 2008. Climate anomalies provide opportunities for largescale mapping of non-native plant abundance in desert grasslands. Diversity and Distributions 14, 875-884. doi:10.1111/j.1472-4642.2008.00500.x.

Jacquemoud, S., Verhoef, W., Baret, F., Bacour, C., Zarco-Tejada, P.J., Asner, G.P., François, C., Ustin, S.L., 2009. PROSPECT+SAIL models: A review of use for vegetation characterization. Remote Sensing of Environment 113, S56-S66. doi:10. $1016 /$ j.rse.2008.01.026. 
Kattenborn, T., Lopatin, J., Förster, M., Braun, A., Fassnacht, F.E., 2019. UAV data as alternative to field sampling to map woody invasive species based on combined Sentinel-1 and Sentinel-2 data. Remote Sensing of Environment 227, 61-73. doi:10. $1016 / j . r s e .2019 .03 .025$.

Ketner-Oostra, R., Sýkora, K.V., 2004. Decline of lichen-diversity in calcium-poor coastal dune vegetation since the 1970s, related to grass and moss encroachment. Phytocoenologia , 521-549doi:10.1127/0340-269X/2004/0034-0521.

Klinck, J., 2009. The alien invasive moss Campylopus introflexus in the Danish coastal dune system. Masterarbeit ed., Copenhagen University.

Kokaly, R.F., Asner, G.P., Ollinger, S.V., Martin, M.E., Wessman, C.A., 2009. Characterizing canopy biochemistry from imaging spectroscopy and its application to ecosystem studies. Remote Sensing of Environment 113, 78-91. doi:10.1016/j.rse.2008. 10.018 .

Kumschick, S., Bacher, S., Dawson, W., Heikkilä, J., Sendek, A., Pluess, T., Robinson, T., Kühn, I., 2012. A conceptual framework for prioritization of invasive alien species for management according to their impact. NeoBiota 15, 69-100. doi:10.3897/neobiota.15.3323.

Latombe, G., Pyšek, P., Jeschke, J.M., Blackburn, T.M., Bacher, S., Capinha, C., Costello, M.J., Fernández, M., Gregory, R.D., Hobern, D., Hui, C., Jetz, W., Kumschick, S., McGrannachan, C., Pergl, J., Roy, H.E., Scalera, R., Squires, Z.E., Wilson, J.R.U., Winter, M., Genovesi, P., McGeoch, M.A., 2016. A vision for global monitoring of biological invasions. Biological Conservation 213, 295-308. doi:10.1016/j.biocon.2016.06.013

Liao, C., Peng, R., Luo, Y., Zhou, X., Wu, X., Fang, C., Chen, J., Li, B., 2008. Altered ecosystem carbon and nitrogen cycles by plant invasion: a meta-analysis. New Phytologist 177, 706-714. doi:10.1111/j.1469-8137.2007.02290.x.

Lopatin, J., Dolos, K., Kattenborn, T., Fassnacht, F.E., 2019. How canopy shadow affects invasive plant species classification in high spatial resolution remote sensing. Remote Sensing in Ecology and Conservation doi:10.1002/rse2.109.

McAlpine, K.G., Lamoureaux, S.L., Westbrooke, I., 2015. Ecological impacts of ground cover weeds in New Zealand lowland forests. New Zealand Journal of Ecology 39, $50-60$.

McGeoch, M.A., Genovesi, P., Bellingham, P.J., Costello, M.J., McGrannachan, C., Sheppard, A., 2016. Prioritizing species, pathways, and sites to achieve conservation targets for biological invasion. Biological Invasions 18, 299-314. doi:10.1007/s10530015-1013-1.

Mehmood, T., Ahmed, B., 2016. The diversity in the applications of partial least squares: an overview. Journal of Chemometrics 30, 4-17. doi:10.1002/cem.2762. 
Miao, X., Gong, P., Swope, S., Pu, R., Carruthers, R., Anderson, G.L., Heaton, J.S., Tracy, C.R., 2006. Estimation of yellow starthistle abundance through CASI-2 hyperspectral imagery using linear spectral mixture models. Remote Sensing of Environment 101, 329-341. doi:10.1016/j.rse.2006.01.006.

Muggeo, V.M.R., 2003. Estimating regression models with unknown break-points. Statistics in Medicine 22, 3055-3071. doi:10.1002/sim.154.

Muggeo, V.M.R., 2008. segmented: an R package to fit regression models with brokenline relationships. R News 8, 20-25.

Müllerová, J., Brůna, J., Dvořák, P., Bartaloš, T., Vítková, M., 2016. Does the data resolution/origin matter? satellite, airborne and Uav imagery to tackle plant invasions. ISPRS - International Archives of the Photogrammetry, Remote Sensing and Spatial Information Sciences 41B7, 903-908. doi:10.5194/isprs-archives-XLI-B7-903-2016.

Neta, T., Cheng, Q., Bello, R.L., Hu, B., 2011. Development of new spectral reflectance indices for the detection of lichens and mosses moisture content in the Hudson Bay Lowlands, Canada. Hydrological Processes 25, 933-944. doi:10.1002/hyp.7878.

Ollinger, S.V., 2011. Sources of variability in canopy reflectance and the convergent properties of plants. New Phytologist 189, 375-394. doi:10.1111/j.1469-8137.2010. $03536 . \mathrm{x}$

Panetta, F.D., Gooden, B., 2017. Managing for biodiversity: impact and action thresholds for invasive plants in natural ecosystems. NeoBiota 34, 53-66. doi:10.3897/ neobiota.34.11821.

Parker, I.M., Simberloff, D., Lonsdale, W.M., Goodell, K., Wonham, M., Kareiva, P.M., Williamson, M.H., Holle, B.V., Moyle, P.B., Byers, J.E., Goldwasser, L., 1999. Impact: toward a framework for understanding the ecological effects of invaders. Biological Invasions 1, 3-19. doi:10.1023/A:1010034312781.

Pauchard, A., García, R.A., Peña, E., González, C., Cavieres, L.A., Bustamante, R.O., 2008. Positive feedbacks between plant invasions and fire regimes: Teline monspessulana (L.) K. Koch (Fabaceae) in central Chile. Biological Invasions 10, 547-553. doi:10.1007/s10530-007-9151-8.

Peerbhay, K., Mutanga, O., Lottering, R., Bangamwabo, V., Ismail, R., 2016. Detecting bugweed (Solanum mauritianum) abundance in plantation forestry using multisource remote sensing. ISPRS Journal of Photogrammetry and Remote Sensing 121, 167-176. doi:10.1016/j.isprsjprs.2016.09.014.

Peterson, E.B., 2005. Estimating cover of an invasive grass (Bromus tectorum) using tobit regression and phenology derived from two dates of Landsat ETM+ data. International Journal of Remote Sensing 26, 2491-2507. doi:10.1080/01431160500127815. 
Pinheiro, J., Bates, D., DebRoy, S., Sarkar, D., R Core Team, 2018. nlme: Linear and nonlinear mixed effects models, $\mathrm{R}$ package version 3.1-137. URL: https://CRAN.Rproject.org/package=nlme.

Powell, K.I., Chase, J.M., Knight, T.M., 2013. Invasive plants have scale-dependent effects on diversity by altering species-area relationships. Science 339, 316-318. doi:10 . $1126 /$ science. 1226817 .

Pyšek, P., Jarošík, V., Hulme, P.E., Pergl, J., Hejda, M., Schaffner, U., Vilà, M., 2012. A global assessment of invasive plant impacts on resident species, communities and ecosystems: the interaction of impact measures, invading species' traits and environment. Global Change Biology 18, 1725-1737. doi:10.1111/j.1365$2486.2011 .02636 \cdot x$.

R Core Team, 2018. R: A Language and Environment for Statistical Computing. R Foundation for Statistical Computing, Vienna, Austria. URL: https://www.Rproject.org/.

Rascher, K.G., Große-Stoltenberg, A., Máguas, C., Werner, C., 2011. Understory Invasion by Acacia longifolia Alters the Water Balance and Carbon Gain of a Mediterranean Pine Forest. Ecosystems 14, 904. doi:10.1007/s10021-011-9453-7.

Rejmanek, M., J. Pitcairn, M., 2002. When is eradication of exotic pest plants a realistic goal?, in: Veitch, C.R., Clout, M.N. (Eds.), Turning the Tide: The Eradication of Invasive Species. IUCN, Gland and Cambridge, pp. 249-253.

Roberts, D.R., Bahn, V., Ciuti, S., Boyce, M.S., Elith, J., Guillera-Arroita, G., Hauenstein, S., Lahoz-Monfort, J.J., Schröder, B., Thuiller, W., Warton, D.I., Wintle, B.A., Hartig, F., Dormann, C., 2017. Cross-validation strategies for data with temporal, spatial, hierarchical, or phylogenetic structure. Ecography 40, 913-929. doi:10.1111/ecog.02881.

Rocchini, D., Andreo, V., Förster, M., Garzon-Lopez, C.X., Gutierrez, A.P., Gillespie, T.W., Hauffe, H.C., He, K.S., Kleinschmit, B., Mairota, P., Marcantonio, M., Metz, M., Nagendra, H., Pareeth, S., Ponti, L., Ricotta, C., Rizzoli, A., Schaab, G., Zebisch, M., Zorer, R., Neteler, M., 2015. Potential of remote sensing to predict species invasions: A modelling perspective. Progress in Physical Geography: Earth and Environment 39, 283-309. doi:10.1177/0309133315574659.

Shackleton, R.T., Shackleton, C.M., Kull, C.A., 2019. The role of invasive alien species in shaping local livelihoods and human well-being: A review. Journal of Environmental Management 229, 145-157. doi:10.1016/j.jenvman.2018.05.007.

Simpson, E.H., 1949. Measurement of diversity. Nature 163, 688. doi:10.1038/163688a0.

Skowronek, S., Asner, G.P., Feilhauer, H., 2017a. Performance of one-class classifiers for invasive species mapping using airborne imaging spectroscopy. Ecological Informatics 37, 66-76. doi:10.1016/j.ecoinf.2016.11.005. 
Skowronek, S., Ewald, M., Isermann, M., Kerchove, R.V.D., Lenoir, J., Aerts, R., Warrie, J., Hattab, T., Honnay, O., Schmidtlein, S., Rocchini, D., Somers, B., Feilhauer, H., 2017b. Mapping an invasive bryophyte species using hyperspectral remote sensing data. Biological Invasions 19, 239-254. doi:10.1007/s10530-016-1276-1.

Skowronek, S., Van De Kerchove, R., Rombouts, B., Aerts, R., Ewald, M., Warrie, J., Schiefer, F., Garzón-López, C., Hattab, T., Honnay, O., Lenoir, J., Rocchini, D., Schmidtlein, S., Somers, B., Feilhauer, H., 2018. Transferability of species distribution models for the detection of an invasive alien bryophyte using imaging spectroscopy data. International Journal of Applied Earth Observation and Geoinformation 68, 61-72. doi:10.1016/j.jag.2018.02.001

Somers, B., Asner, G.P., 2013. Invasive species mapping in Hawaiian rainforests using multi-temporal Hyperion spaceborne imaging spectroscopy. IEEE Journal of Selected Topics in Applied Earth Observations and Remote Sensing 6, 351-359. doi:10.1109/ JSTARS.2012.2203796

Somers, B., Asner, G.P., Tits, L., Coppin, P., 2011. Endmember variability in spectral mixture analysis: a review. Remote Sensing of Environment 115, 1603-1616. doi:10. $1016 /$ j.rse.2011.03.003.

Sterckx, S., Vreys, K., Biesemans, J., Iordache, M.D., Bertels, L., Meuleman, K., 2016. Atmospheric correction of APEX hyperspectral data. Miscellanea Geographica 20, 16-20. doi:10.1515/mgrsd-2015-0022.

Ustin, S.L., Gitelson, A.A., Jacquemoud, S., Schaepman, M., Asner, G.P., Gamon, J.A., Zarco-Tejada, P., 2009. Retrieval of foliar information about plant pigment systems from high resolution spectroscopy. Remote Sensing of Environment 113, S67-S77. doi:10.1016/j.rse.2008.10.019.

Vaz, A.S., Alcaraz-Segura, D., Campos, J.C., Vicente, J.R., Honrado, J.P., 2018. Managing plant invasions through the lens of remote sensing: a review of progress and the way forward. Science of The Total Environment 642, 1328-1339. doi:10.1016/j . scitotenv.2018.06.134.

Vilà, M., Espinar, J.L., Hejda, M., Hulme, P.E., Jarošík, V., Maron, J.L., Pergl, J., Schaffner, U., Sun, Y., Pyšek, P., 2011. Ecological impacts of invasive alien plants: a meta-analysis of their effects on species, communities and ecosystems. Ecology Letters 14, 702-708. doi $10.1111 / \mathrm{j} .1461-0248.2011 .01628 . \mathrm{x}$.

Vogels, J., Nijssen, M., Verberk, W., Esselink, H., 2005. Effects of moss-encroachment by Campylopus introflexus on soil-entomofauna of dry-dune grasslands (Violocorynephoretum). Proceedings of the Netherlands Entomological Society Meeting 16, $71-81$.

Vreys, K., Iordache, M.D., Biesemans, J., Meuleman, K., 2016. Geometric correction of APEX hyperspectral data. Miscellanea Geographica 20, 11-15. doi:10.1515/mgrsd2016-0006. 
Wold, S., Ruhe, A., Wold, H., Dunn, W., I., 1984. The Collinearity Problem in Linear Regression. The Partial Least Squares (PLS) Approach to Generalized Inverses. SIAM Journal on Scientific and Statistical Computing 5, 735-743. doi:10.1137/0905052 